09

\title{
Оптические свойства объемных монокристаллов нитрида галлия, выращенных методом хлорид-гидридной газофазной эпитаксии
}

\author{
(C) В.Ф. Агекян, Е.В. Борисов, А.Ю. Серов, Н.Г. Философов \\ Санкт-Петербургский государственный университет, \\ Санкт-Петербург, Россия \\ E-mail: v.agekyan@spbu,ru \\ (Поступила в Редакцию 11 апреля 2017 г.)
}

\begin{abstract}
Кристалл нитрида галлия толщиной $5 \mathrm{~mm}$ был выращен методом хлорид-гидридной газофазной эпитаксии на сапфировой подложке, от которой кристалл отделился в процессе остывания. На ранней стадии был реализован трехмерный режим роста с последующей сменой на двумерный режим. В нескольких характерных областях образца исследованы спектры экситонного отражения, экситонной люминесценции и рамановского рассеяния. Анализ этих спектров и сравнение с ранее полученными данными для тонких эпитаксиальных слоев $\mathrm{GaN}$ с широким диапазоном легирования кремнием позволили сделать выводы о качестве кристаллической решетки в этих характерных областях образца.
\end{abstract}

Работа выполнена в рамках инициативной темы СПбГУ № 11.52.454.2016, для исследования спектров рамановского рассеяния использовалось оборудование Ресурсного центра СПбГУ „Оптические и лазерные методы исследования вещества“.

DOI: $10.21883 /$ FTT.2017.12.45237.120

\section{1. Введение}

Нитрид галлия $(\mathrm{GaN})$ - прямозонный полупроводник с широкой запрещенной зоной, на основе которого в настоящее время формируется новое поколение электроники и выпускается широкий спектр электронных приборов - от светодиодов и лазеров до силовых и СВЧ-приборов и элементов цифровой электроники. В настоящее время существуют проблемы с коммерчески доступными высококачественными подложками $\mathrm{GaN}$, вследствие чего большинство приборов до сих пор производится по гетероэпитаксиальной технологии на инородных подложках (кремний, сапфир, карбид кремния и др.). Это приводит к образованию в приборных слоях $\mathrm{GaN}$ механических напряжений и значительного количества дислокаций несоответствия, что ухудшает характеристики материала и снижает рабочие параметры приборов. Использование подложек из нитрида галлия позволяет получать приборные структуры более высокого качества, и этим определяется интерес к развитию способов получения механически ненапряженных объемных кристаллов $\mathrm{GaN}$ с низкой плотностью дислокаций и к изучению их физических свойств. Существующая техника расслаивания объемных кристаллов $\mathrm{GaN}$ позволяет получать серии высококачественных подложек.

В настоящей работе исследованы оптические свойства ненапряженных объемных кристаллов $\mathrm{GaN}$, выращенных методом хлорид-гидридной газофазной эпитаксии (HVPE).

\section{2. Технология изготовления объемных кристаллов нитрида галлия}

Образцы нитрида галлия были выращены методом HVPE в специально сконструированном реакторе вертикального типа, позволяющем получать объемные кристаллы диаметром до $75 \mathrm{~mm}$ на шести подложках одновременно. В качестве рабочих газов использовались аммиак (чистота 99.99995\%) и хлористый водород (чистота 99.999\%), транспортирующим газом являлся азот (чистота 99.99999\%), как источник $\mathrm{Ga}$ применялся металлический галлий (чистота 99.99999\%). Скорость роста кристаллов $\mathrm{GaN}$ составляла $0.2 \mathrm{~mm} / \mathrm{h}$ при температуре $990^{\circ} \mathrm{C}$ и давлении в реакторе 700 Torr, парциальные давления $\mathrm{GaCl}$ и $\mathrm{NH}_{3}$ составляли $0.8 \cdot 10^{3}$ и $2 \cdot 10^{4} \mathrm{~Pa}$ соответственно. Продолжительность ростового процесса варьировалась от 3 до $25 \mathrm{~h}$. Затравками для получения объемных кристаллов служили пленки нитрида галлия толщиной $40 \mu \mathrm{m}$, выращенные в HVPE-реакторе на подложках из сапфира с ориентацией (0001). Особенность технологического процесса состоит в переходе от начального трехмерного режима роста $\mathrm{GaN}$ к двумерному режиму, что позволяет предотвратить растрескивание кристалла в реакторе вследствие ростовых напряжений [1]. После завершения роста при остывании кристаллов до комнатной температуры происходило их спонтанное отделение от сапфировой подложки вследствие различия коэффициентов температурного расширения нитрида галлия и сапфира (при остывании тонких кристаллов часто наблюдалось их поперечное растрескивание). В результате были получены кристаллы нитрида 
галлия диаметром $52 \mathrm{~mm}$ с толщиной от 0.6 до $5 \mathrm{~mm}$. Поверхность образцов является зеркально гладкой, на поверхности присутствуют ростовые дефекты - ямки, имеющие форму инверсных гексагональных пирамид, происхождение которых обсуждается в работе [2].

\section{3. Оптические свойства объемных кристаллов GaN}

Для проведения измерений оптическими методами (отражение, фотолюминесценция, рамановское рассеяние) образец $\mathrm{GaN}$ толщиной $5 \mathrm{~mm}$ был расколот параллельно плоскости (1120). Спектры фотолюминесценции и отражения исследовались на спектрометре МДР-204-2 (производство ЛОМО-Фотоника), люминесценция возбуждалась непрерывным гелий-кадмиевым лазером с энергией фотонов $3.81 \mathrm{eV}$, исследование рамановского рассеяния проводилось на спектрометре SENTERRA (производство Bruker). Спектры отражения, люминесценции и рамановского рассеяния изучались в характерных областях объемного образца GaN: нижняя и верхняя поверхности; боковая поверхность (скол) в точках, соответствующих двум указанным выше режимам роста; поверхность инверсных пирамид (см. схему на рис. 2).

3.1. Спектры отражения. В спектре отражения от верхней части боковой поверхности - скола, в

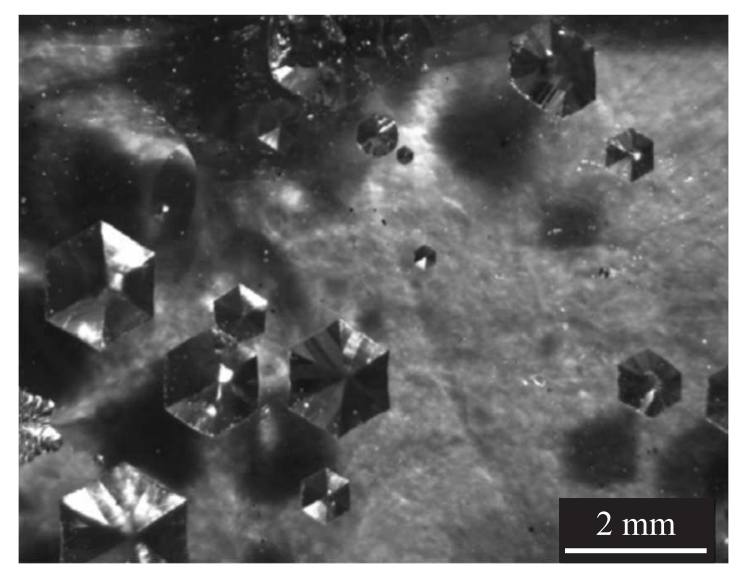

Рис. 1. Поверхность кристалла $\mathrm{GaN}$ с инвертированными гексагональными пирамидами.

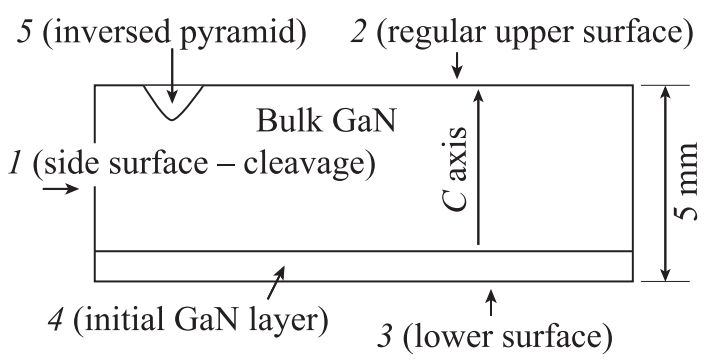

Separated sapphire substrate

Рис. 2. Схема характерных областей кристалла $\mathrm{GaN}$, в которых исследовались оптические характеристики (см. текст).

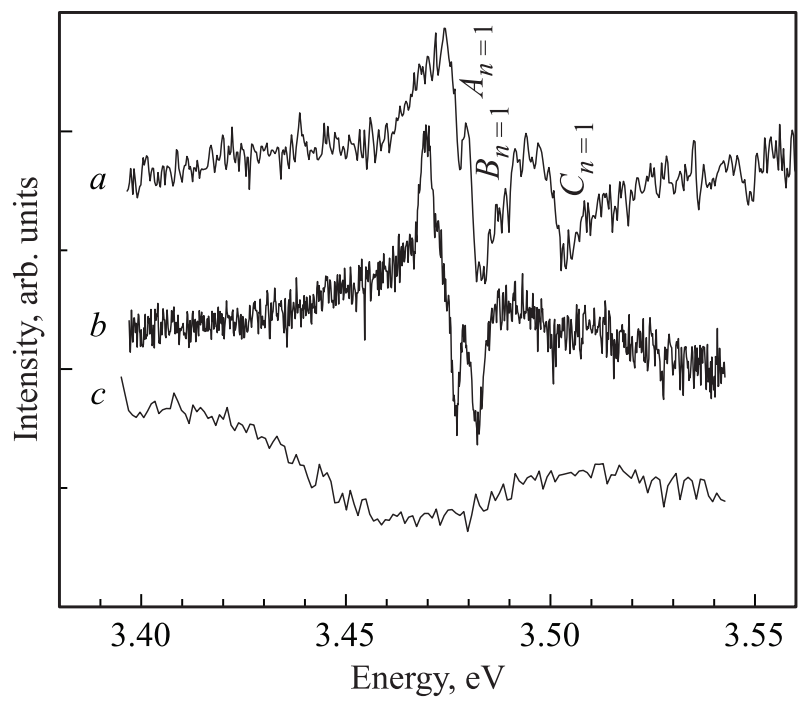

Рис. 3. Резонансы свободных экситонов $A_{n=1}, B_{n=1}, C_{n=1}$ (головные линии трех экситонных серий) в спектрах отражения $\mathrm{GaN}, T=5 \mathrm{~K} ; a, b, c$ соответствуют точкам 2, 1, 3 на рис. 2.

плоскости которого лежит гексагональная ось кристалла (точка 1), наблюдается резкая структура, соответствующая резонансам $A, B$ и $C$ - экситонов нитрида галлия с главным квантовым числом $n=1$ (рис. 3). Эта же структура присутствует в спектре отражения от верхней плоскости образца (точка 2). Расхождение энергетического положения экситонных резонансов с известными данными для ненапряженных кристаллов $\mathrm{GaN}$ [3] составляет не более $1 \mathrm{meV}$, что свидетельствует об отсутствии существенных напряжений в верхних слоях исследуемого образца. В спектре отражения от плоскости, примыкавшей к сапфировой подложке (точка 3), экситонная структура сильно размыта. Уширение экситонного спектра отражения от этой области кристалла не сопровождается энергетическим сдвигом, и можно сделать вывод, что уширение экситонных резонансов определяется высокой концентрацией дефектов, а не механическими напряжениями. Отметим, что подобное уширение экситонной структуры наблюдалось в спектрах отражения эпитаксиальных слоев GaN c концентрацией кремния, превышающей $10^{18} \mathrm{~cm}^{-3}$ [4].

3.2. Спектры люминесценции. На рис. 4 представлены спектры люминесценции, полученные от указанных выше характерных областей кристалла GaN. Для сравнения на рис. 5 приведены спектры люминесценции слоев $\mathrm{GaN}$ толщиной $4 \mu \mathrm{m}$, выращенных методом хлорид-гидридной эпитаксии с диапазоном концентрации донорной примеси кремния $10^{16}-10^{19} \mathrm{~cm}^{-3}[4]$.

Спектр излучения поверхности образца в точке 2 содержит полосы бесфононного излучения свободных экситонов, экситонов, связанных на нейтральных доноpax и акцепторах, а также их фононные реплики, соответствующие рождению до пяти продольных оптических (LO)-фононов решетки GaN с энергией $91 \mathrm{meV}$ (принадлежность отдельных фононных реплик к различным механизмам излучения указана на рис. 6). Сопоставление 


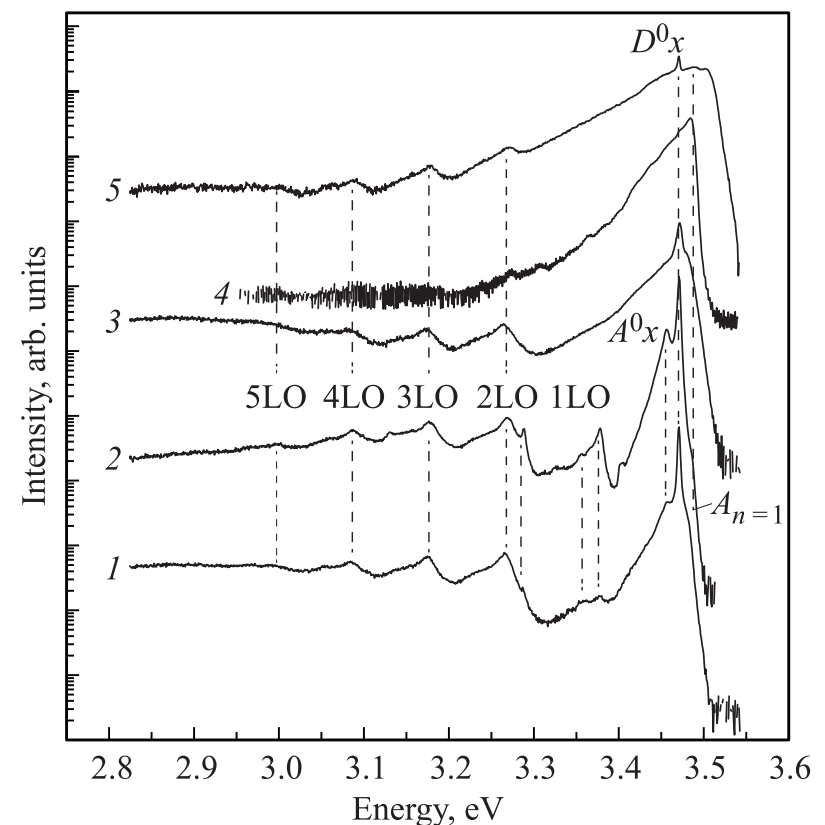

Рис. 4. Спектры люминесценции объемного образца GaN при $T=5 \mathrm{~K}$ (полулогарифмический масштаб). Цифры слева соответствуют точкам на рис. 2. $A_{n=1}-$ свободный экситон, $D^{0} x$ и $A^{0} x$ - экситоны, связанные на нейтральных донорах и акцепторах, 1-5 LO - фононные реплики экситонного излучения с рождением продольных оптических фононов.

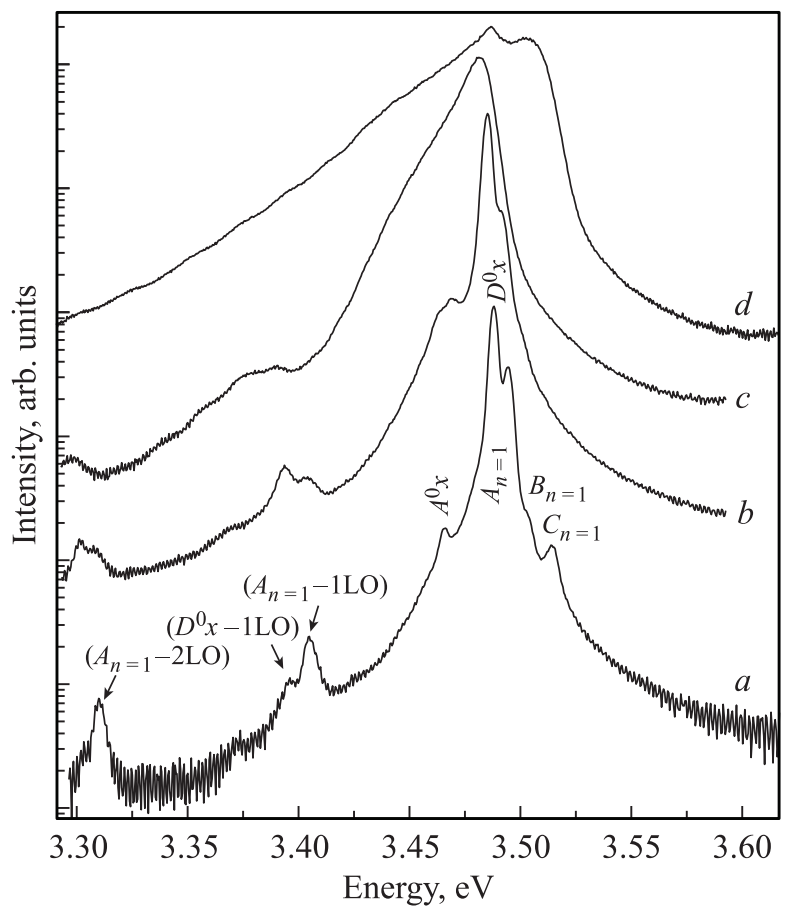

Рис. 5. Спектры люминесценции слоев $\mathrm{GaN}$ толщиной $4 \mu \mathrm{m}$, выращенных на сапфировых подложках методом хлор-гидридной эпитаксии, $T=5 \mathrm{~K}$ [4]. Концентрации донорной примеси кремния составляют $4 \cdot 10^{16}(a), 3 \cdot 10^{17}(b), 3 \cdot 10^{18}(c)$ и $5 \cdot 10^{19}(d) \mathrm{cm}^{-3} . A_{n=1}, B_{n=1}, C_{n=1}$ - свободные экситоны, $D^{0} x$ и $A^{0} x$ - экситоны, связанные на нейтральных донорах и акцепторах, $\left(A_{n-1}-1 \mathrm{LO}\right),\left(A_{n=1}-2 \mathrm{LO}\right),\left(D^{0} x-1 \mathrm{LO}\right)-$ фононные реплики связанных экситонов $A_{n=1}$ и $D^{0} x$ с рождением LO-фононов.

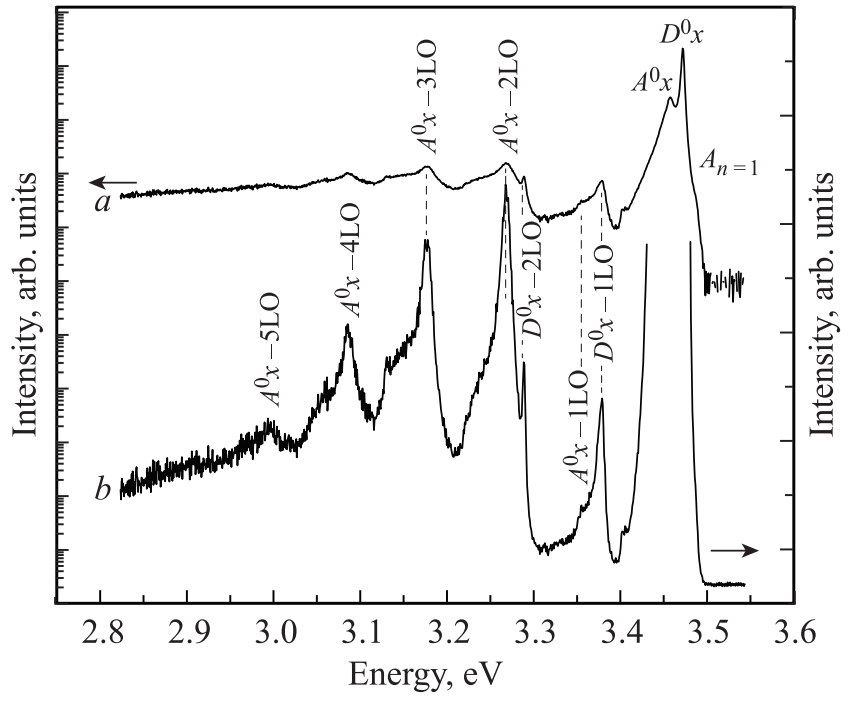

Рис. 6. Спектр люминесценции поверхности GaN (точка 2 на рис. 2) в полулогарифмическом масштабе $(a)$ и фононные реплики этого спектра в линейном масштабе $(b), T=5 \mathrm{~K}$. $\left(A^{0} x-m \mathrm{LO}\right)$ и $\left(D^{0} x-m \mathrm{LO}\right)-$ фононные реплики излучения связанных экситонов $A^{0} x$ и $D^{0} x$ с рождением LO-фононов.

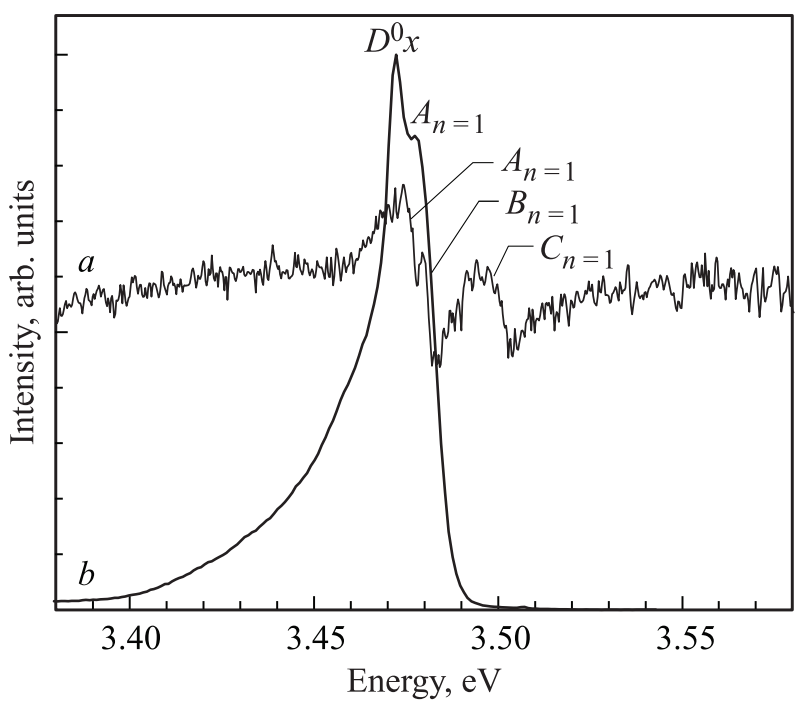

Рис. 7. Сопоставление спектров отражения и люминесценции поверхности $\mathrm{GaN}$ (точка 2 на рис. 3) в линейном масштабе, $T=5 \mathrm{~K}$.

спектров отражения и люминесценции в точке 2 (рис. 7) подтверждает, что самая высокоэнергетическая полоса излучения соответствует свободному экситону серии $A$ с главным квантовым числом $n=1$.

Спектр излучения скола боковой поверхности образца (точка 1) также хорошо структурирован, обращает на себя внимание малая интенсивность фононной реплики свободного экситона, которая соответствует рождению одного LO-фонона. Известно, что излучательная аннигиляция свободного экситона с рождением одного фонона является при низких температурах запрещенным процессом для идеального кристалла [5], так что малая 
интенсивность соответствующей полосы излучения свидетельствует о совершенстве кристаллической решетки.

Таким образом, можно сделать вывод о хорошем качестве исследуемого кристалла $\mathrm{GaN}$ в точках 1 и 2 , спектры люминесценции от этих областей близки к спектрам высококачественных тонких эпитаксиальных слоев $\mathrm{GaN}$, легированных донорами на уровне $10^{16} \mathrm{~cm}^{-3}$.

Спектр излучения боковой поверхности (скола) в точке 4 , соответствующей начальной стадии роста объемного кристалла (трехмерный режим), уширен, четкая структура, в отличие от спектров в точках 1 и 2 , в нем отсутствует. Это свидетельствует о более низком качестве кристаллической решетки в этой области, ее спектр излучения аналогичен спектру тонких эпитаксиальных слоев с уровнем легирования $10^{18} \mathrm{~cm}^{-3}$.

Спектры люминесценции от нижней плоскости образца, контактировавшей с подложкой, и спектры от поверхности инверсных гексагональных пирамид (точки 3 и 5) также уширены, отдельные компоненты бесфононного излучения свободных и связанных экситонов в них не разрешаются. Для спектра в точке 5 характерно сильное расширение в область высоких энергий, что, как показано в работе [4], является особенностью спектра кристаллов $\mathrm{GaN}$ с концентрацией кремния на уровне $10^{19} \mathrm{~cm}^{-3}$ (рис. 5). Можно заключить, что слои образца, контактировавшие с сапфировой подложкой, имеют высокую концентрацию дефектов. Это могут быть как дислокации, так и примеси, внедрившиеся в процессе роста. Что касается поверхностей инверсных пирамид, эти слои растут медленнее, чем те слои, которые формируют регулярную поверхность образца, что, повидимому, способствует накоплению в них примесей.

3.3. Спектры рамановского рассеяния. На рис. 8 представлены нормированные по интенсивности компоненты $E_{2}$ (high)-спектры рамановского рассеяния света от верхней и нижней плоскостей образца и от поверхности инверсных пирамид (точки 2, 3 и 5). Наряду с известными линиями спектра рассеяния первого порядка $A_{1}(\mathrm{TO}, \mathrm{LO}), E_{1}(\mathrm{TO}, \mathrm{LO}), E_{2}$ (low, high) наблюдаются более слабые компоненты в областях 317 , $410,850-1000$ и $1150-1500 \mathrm{~cm}^{-1}$. Эти компоненты согласно результатам теоретико-группового анализа [6] соответствуют рассеянию более высоких порядков акустическим обертонам, комбинированным акустическим и оптическим колебаниям, оптическим обертонам. Спектр рассеяния от верхней плоскости кристалла (точка 2) содержит только эти составляющие, относящиеся к регулярной решетке $\mathrm{GaN}$. B спектре рассеяния от поверхностей инверсных пирамид присутствует широкая полоса с максимумом около $420 \mathrm{~cm}^{-1}$, происхождение которой обусловлено дефектами. В спектре рассеяния от нижней плоскости образца наблюдаются дополнительные компоненты с максимумами 509 и $653 \mathrm{~cm}^{-1}$. Эта область кристалла контактировала с подложкой, и дополнительные максимумы можно интерпретировать как локальные колебания, индуцированные дефектами примесного типа.

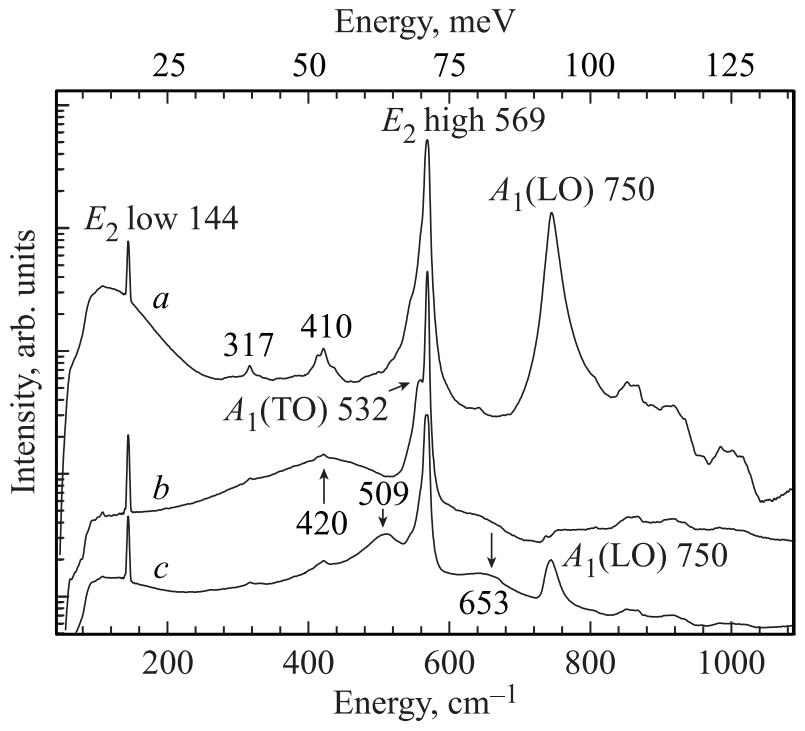

Рис. 8. Спектры рамановского рассеяния $\mathrm{GaN}$ при комнатной температуре: $a-$ поверхность кристалла (точка 2), $b-$ инверсная пирамида (точка 5), $c$ - плоскость, контактировавшая с сапфировой подложкой (точка 3). Стрелками отмечены компоненты спектра, индуцированные дефектами: широкая полоса в спектре $b$ с максимумом $420 \mathrm{~cm}^{-1}$, полосы $317,420,509$ и $653 \mathrm{~cm}^{-1}$ в спектре $c$. Структура в области выше $800 \mathrm{~cm}^{-1}$ соответствует рассеянию с участием двух и более фононов.

Итак, в результате проведенных оптических исследований объемного кристалла нитрида галлия, выращенного методом хлорид-гидридной газофазной эпитаксии, получены сведения о качестве кристаллической решетки в характерных областях кристалла.

Авторы выражают благодарность Ю.Г. Шретеру за предоставление объемного кристалла $\mathrm{GaN}$ для оптических исследований и за полезное обсуждение результатов.

\section{Список литературы}

[1] V. Voronenkov, N. Bochkareva, R. Gorbunov, P. Latyshev, Y. Lelikov, Y. Rebane, A. Tsyuk, A. Zubrilov, Y. Shreter. Jpn. J. Appl. Phys. 52, 08JE14 (2013).

[2] V.V. Voronenkov, N.I. Bochkareva, R.I. Gorbunov, P.E. Latyshev, Y.S. Lelikov, Y.T. Rebane, A.I. Tsyuk, A.S. Zubrilov, U.W. Popp, M. Strafela, H.P. Strunk, Y.G. Shreter. Phys. Status Solidi C 10, 468 (2013).

[3] M. Reshchikov, H. Morkoç. J. Appl. Phys. 97, 061031 (2005).

[4] V.F. Agekyan, E.V. Borisov, L.E. Vorob'ev, G.A. Melent'ev, Y. Nykännen, L. Riuttanen, A.Yu. Serov, S. Suihkonen, O. Svensk, N.G. Filosofov, V.A. Shalygin, L.A. Shelukhin. Phys. Solid State 57, 787 (2015) [ФTT 57, 768 ( 2015)].

[5] S.A. Permogorov. In Excitons / Ed. E.I. Rashba, M.D. Sturge. North-Holland Publ. Comp. (1982). 177 p.

[6] H. Siegle, G. Karzmarczyk, L. Filippidis, A.P. Litvinchuk, A. Hoffman, C. Thonsen. Phys. Rev. B 55, 7000 (1997). 